\title{
Author Correction: Parametric dependence of hot electron relaxation timescales on electron-electron and electron-phonon interaction strengths
}

\author{
Richard B. Wilson \& Sinisa Coh
}

Correction to: Communications Physics https://doi.org/10.1038/s42005-020-00442-x, published online 9 October 2020.

The original version of this Article contained one sentence in the fifth paragraph of the section "Methods: Collision integrals", which read: "The Kernel function $K\left(\varepsilon, \varepsilon^{\prime}, \varepsilon^{\prime \prime}, \varepsilon^{\prime \prime}\right)$ is the average square of the electron-electrontermines the average e-e quasiparticle lifetime of electronic states on the constant energy surface $\varepsilon$ ".

The new version replaces this sentence with: "The Kernel function $K\left(\varepsilon, \varepsilon^{\prime}, \varepsilon^{\prime \prime}, \varepsilon^{\prime \prime}\right)$ is the average square of the electron-electron matrix element between electrons on a constant energy surface $\varepsilon$ with electronic states on constant energy surfaces defined by $\varepsilon^{\prime}$, $\varepsilon^{\prime \prime}$, and $\varepsilon^{\prime \prime}$ [28]. The Kernel function determines the average e-e quasi-particle lifetime of electronic states on the constant energy surface $\varepsilon$."

The above have been corrected in both the PDF and HTML versions of the Article.

Published online: 01 December 2020

\footnotetext{
(c) (i) Open Access This article is licensed under a Creative Commons Attribution 4.0 International License, which permits use, sharing, adaptation, distribution and reproduction in any medium or format, as long as you give appropriate credit to the original author(s) and the source, provide a link to the Creative Commons license, and indicate if changes were made. The images or other third party material in this article are included in the article's Creative Commons license, unless indicated otherwise in a credit line to the material. If material is not included in the article's Creative Commons license and your intended use is not permitted by statutory regulation or exceeds the permitted use, you will need to obtain permission directly from the copyright holder. To view a copy of this license, visit http://creativecommons.org/licenses/by/4.0/.
}

(c) The Author(s) 2020 